\title{
The accuracy of self-reported weight by overweight and obese women in an outpatient setting
}

\author{
Katja Rossouw ${ }^{1, *}$, Marjanne Senekal ${ }^{2}$ and Ilse Stander ${ }^{3}$ \\ ${ }^{1}$ Chronic Diseases of Lifestyle Programme, Medical Research Council, Parowvallei, South Africa: ${ }^{2}$ Department of \\ Consumer Science, University of Stellenbosch, South Africa: ${ }^{3}$ Centre for Epidemiological Research in Southern \\ Africa, Medical Research Council, Parowvallei, South Africa
}

Submitted 21 January 1999: Accepted 23 May 2000

\begin{abstract}
Objective: To investigate the accuracy of self-reported weight of overweight and obese women and characterisation of under-, correct- and over-reporters based on a number of related variables.

Design: Weight was self-reported before entering the study. At baseline, actual weight was recorded, and demographic, health, nutritional, psychological and physical activity questionnaires were completed.

Setting: A hospital outpatient department.

Subjects: Participants were 131 women aged 18-64 years with a body mass index $(\mathrm{BMI}) \geq 28$ attending a Comprehensive Weight Management Programme.

Outcome measures: The accuracy of self-reported weight was investigated for the total group, and the subjects were then categorised into three groups according to accuracy of self-reported weight (under-, correct- and over-reporters). The relationship between these accuracy groups and demographic, health, nutritional, and psychological variables and physical activity was examined, to characterise the under-, correct- and over-reporters.

Results: Although not statistically significantly different, the total group of women tended to underestimate their weight by $0.8( \pm 3.6) \mathrm{kg}$. Categorisation according to the accuracy groups revealed that $29 \%$ underestimated their weight by $2 \mathrm{~kg}$ or more, $19 \%$ overestimated their weight by $2 \mathrm{~kg}$ or more, and only $52 \%$ correctly estimated their weight within $2 \mathrm{~kg}$. Some trends and statistically significant differences between the accuracy groups concerning certain variables, e.g. height, age, income, education, contraceptive pill usage, smoking and food choices were evident.

Conclusions: Self-reported weight of a group of overweight/obese individuals may be a valid and reliable indicator of actual weight, but self-reported weight of an overweight/obese individual can not be interpreted similarly. Further research is necessary to ensure reliable characterisation of under-, over- and correct reporters.
\end{abstract}

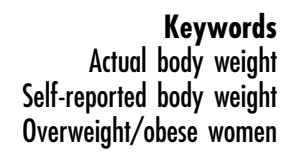

Keywords Self-reported body weight Overweight/obese women
Weight and height measurements, as well as the derived indexes of relative weight (e.g. the Quetelet index), are widely used as indicators of nutritional status in epidemiological and clinical studies ${ }^{1,2}$. These measurements may be obtained in two ways, i.e. direct measurement of, or self-reporting by the study participants ${ }^{1}$. Direct measurement is the most accurate, and is usually the method of choice. Self-reported data are, however, often used in research when direct measurement of weight and height is not possible or practical ${ }^{1}$, owing to large samples, the inaccessibility of respondents, and time or financial restrictions ${ }^{2}$. Examples of such research include studies that are focused on overweight and obese groups, e.g. experimental weight loss programmes where selfreported weight and height are used for preliminary selection of candidates ${ }^{4}$, and longitudinal studies that evaluate the effectiveness of specific weight treatment approaches ${ }^{1}$.

Several factors may influence the validity and reliability of self-reported data, influencing the potential value of such data. These factors include random error in reporting, a tendency to end-digit preference ${ }^{5}$, a systematic tendency in the direction of cultural ideals of the population being studied ${ }^{4}$, the participant's perception of what is socially more acceptable ${ }^{2,3}$, and the perception of participants in weight loss programmes of the researcher's 
expectations $^{2}$. Jalkanen et $a l^{6}{ }^{6}$ mentioned that inaccuracy of self-reported weight may also be associated with personal characteristics. Several studies show systematic underreporting, especially among females ${ }^{4-8}$ and heavier persons $^{3-9}$. The difference between self-reported and actual weight also tends to be greater among older and heavier persons than in younger, lighter persons ${ }^{6}$.

It is recommended by some researchers ${ }^{6}$ that it is not advisable to use self-reported weight when groups consisting of elderly and/or obese persons are studied. However, Tell et $a l^{2}{ }^{2}$ suggest that a correction factor be applied to improve the reliability and validity of the data, while other researchers maintain that self-reported data are accurate enough for epidemiological studies, but not for the assessment of the effect of intervention in individual patients $^{6,7}$.

Very little information is available on the accuracy of selfreported weight and the characteristics of under-, correctand over-reporters among South African overweight and obese females. This information is essential for the interpretation of weight data in formal research concerning weight management where self-reported weight data is the only option. Furthermore, characterisation of under-, correct- and over-reporters based on weight management related variables, could lead to the identification of a group of variables that could be applied to predict accuracy of self-reported weight in similar groups. The aims of this study, therefore, were as follows: (1) to determine whether self-reported weight is a valid and reliable indicator of actual weight in a group of overweight and obese women who had been selected for a weight loss programme in an outpatient setting, (2) to divide the subjects into three accuracy groups, i.e. weight overestimated, weight correctly estimated and weight underestimated, (3) to assess the relationship between the accuracy of self-reported weight and demographic, general health, nutrition related and psychological variables, as well as physical activity, and (4) to characterise the type of person who is inclined to over-report, correctly report or under-report weight, based on the variables mentioned in aim 3 . This report is based on the baseline assessment of a Comprehensive Weight Management Programme (CWMP), which was implemented at the outpatient department of a South African teaching hospital.

\section{Methods}

\section{Subjects}

Subjects were invited to participate in a CWMP at the outpatient department of the teaching hospital by means of an advertisement published in the local media. Respondents had to attend one of the information sessions at the Medical Research Council (MRC) in order to be considered for the programme. A total of 184 (men and women) subjects between 18 and 64 years old with a body mass index $(\mathrm{BMI})^{10} \geq 28$ were selected from the 255 applicants.
The following exclusion criteria were applicable: a history or evidence of ischaemic heart disease, congestive heart failure, pregnancy, psychiatric illness, cancer, AIDS, known kidney and liver disease. Relevant data of the 131 overweight or obese women who were selected, are reported in this paper.

\section{Antbropometric measurements}

For the documentation of self-reported weight, subjects were asked to report weight and height before entering the study. Actual weight and height were measured during the baseline assessment by standardised, registered dietitians at the hospital. Measurements were taken with each subject in light clothing and without shoes. Weight was measured to the nearest $0.1 \mathrm{~kg}$ with a standardised electronic scale. Height was recorded to the nearest $0.1 \mathrm{~cm}$ using a standardised anthropometer. BMI was calculated as weight $(\mathrm{kg}) /$ height $^{2}\left(\mathrm{~m}^{2}\right)$ for both the estimated as well as the actual anthropometric measurements ${ }^{10}$.

\section{Classification according to accuracy of self-reported weight}

No well motivated set of cut-off points for the classification of accuracy of self-reported weight could be found in the literature. Therefore, the following categories (=accuracy groups) were defined for the purpose of this study:

under-reporters: self-reported weight more than $2 \mathrm{~kg}$ below their actual weight

correct reporters: self-reported weight not more than $2 \mathrm{~kg}$ above or below their actual weight

over-reporters: self-reported weight more than $2 \mathrm{~kg}$ above their actual weight

These cut-off points were selected to provide for normal day-to-day weight variation in individuals, and differences in the accuracy of the individual's own scales ${ }^{6}$. Further, because the population consisted of overweight and obese individuals, correct reporters were defined as actual weight $\pm 2 \mathrm{~kg}$ and not $\pm 1 \mathrm{~kg}$, as was used by Jalkanen et al. ${ }^{6}$ for a group of normal weight to obese individuals.

\section{Evaluation of demographic, general bealth and nutrition variables}

Questionnaires were developed to obtain the necessary demographic, general health and nutrition data and these were tested during a pilot study. During the baseline assessment the questionnaires were completed under the supervision of fieldworkers. Demographic and general health data included name, address, age, gender, education level, monthly income, use of the contraceptive pill, weight history and smoking habits. For statistical analyses three education categories were identified, namely school education up to grade 10 , grade 12 and tertiary education. Similarly, three income categories were defined, including R0-2999 per month, R3000-4999 per month and R5000+ per month. The nutrition questionnaires included a non- 
Table 1 The means $( \pm$ SD) of continuous variables for the total group and the three accuracy groups $(n=131)$

\begin{tabular}{|c|c|c|c|c|}
\hline & $>2 \mathrm{~kg}$ under-reported $(n=38)$ & $\pm 2 \mathrm{~kg}$ correct reported $(n=69)$ & $>2 \mathrm{~kg}$ over-reported $(n=24)$ & Total group \\
\hline$\%$ of total group & 29 & 52 & 19 & \\
\hline $\mathrm{Age}^{*}-\mathrm{g}$ & $\begin{array}{c}39.6 \\
( \pm 6.6)\end{array}$ & $\begin{array}{c}42.3 \\
( \pm 10.3)\end{array}$ & $\begin{array}{c}35.5 \\
( \pm 9.5)\end{array}$ & $\begin{array}{c}40.3 \\
( \pm 9.6)\end{array}$ \\
\hline Self-reported weight ${ }^{\star}$ & $\begin{array}{c}108.1 \\
( \pm 18.2)\end{array}$ & $\begin{array}{c}94.5 \\
( \pm 14.9)\end{array}$ & $\begin{array}{c}104.2 \\
( \pm 25.5)\end{array}$ & $\begin{array}{c}100.2 \\
( \pm 19.1)\end{array}$ \\
\hline Actual weight $(\mathrm{kg})^{*}$ & $\begin{array}{c}112.9 \\
( \pm 18.9)\end{array}$ & $\begin{array}{c}94.7 \\
( \pm 14.8)\end{array}$ & $\begin{array}{c}100.0 \\
( \pm 25.5)\end{array}$ & $\begin{array}{c}101.0 \\
( \pm 19.9)\end{array}$ \\
\hline Height $(\mathrm{cm})^{\star}$ & $\begin{array}{l}165.5 \\
( \pm 6.0)\end{array}$ & $\begin{array}{l}161.4 \\
( \pm 6.2)\end{array}$ & $\begin{array}{l}162.5 \\
( \pm 7.1)\end{array}$ & $\begin{array}{l}162.8 \\
( \pm 6.5)\end{array}$ \\
\hline BMI $\left(\mathrm{kg} / \mathrm{m}^{2}\right)^{\dagger}$ & $\begin{array}{c}41.3 \\
( \pm 6.5)\end{array}$ & $\begin{array}{c}36.4 \\
( \pm 5.3)\end{array}$ & $\begin{array}{c}37.6 \\
( \pm 7.9)\end{array}$ & $\begin{array}{c}38.0 \\
( \pm 6.5)\end{array}$ \\
\hline Cigarettes smoked/day* & $\begin{array}{c}30.8 \\
( \pm 20.0)\end{array}$ & $\begin{array}{c}14.4 \\
( \pm 7.3)\end{array}$ & $\begin{array}{c}16.8 \\
( \pm 10.8)\end{array}$ & $\begin{array}{c}19.2 \\
( \pm 14.1)\end{array}$ \\
\hline Nutrition knowledge & $\begin{array}{c}23.1 \\
( \pm 3.3)\end{array}$ & $\begin{array}{c}21.9 \\
( \pm 4.3)\end{array}$ & $\begin{array}{c}22.5 \\
( \pm 3.8)\end{array}$ & $\begin{array}{c}22.3 \\
( \pm 4.0)\end{array}$ \\
\hline
\end{tabular}

* $P \leq 0.04$ (ANOVA).

$\dagger$ Based on actual weight.

quantified food frequency section to assess the frequency of intake of high fat food items, sweets, desserts, soft drinks, alcoholic drinks, vegetables and fresh fruits. Questions concerning usual meal pattern were included as well as a nutrition knowledge questionnaire. The latter contained 30 multiple choice questions taken from standardised nutrition knowledge tests. The validity and reliability of these questions as a nutrition knowledge test were not determined. Therefore, nutrition knowledge was only expressed as the percentage of correct answers with the maximum score (100\%) being 30.

\section{Evaluation of psychological conditions}

To evaluate the relevant psychological variables the following standardised questionnaires were administered by a clinical psychologist: the Beck Inventory ${ }^{11}$ for levels of depression; the Eating Inventory ${ }^{12}$ for the three dimensions of eating behaviour, i.e. cognitive restraint, disinhibition and hunger; a self-esteem questionnaire ${ }^{13}$; a stress vulnerability questionnaire ${ }^{14}$; and a family functioning questionnaire $^{15}$ which measures family adaptability, family cohesion and family satisfaction. Detailed analyses of the psychological evaluations were published elsewhere ${ }^{16}$.

\section{Evaluation of physical activity levels}

For the evaluation of levels of physical activity, including the amount and type of exercise performed per week and activity levels at employment, a questionnaire, developed and tested by a sport physiologist for the purposes of this research, was applied.

\section{Statistical analysis}

The SAS statistical package ${ }^{17}$ was used to analyse the data. Reported and actual weight were compared by means of Student's paired $t$-test. Spearman's rank order correlation, analysis of variance, frequency tables and cross tabulations (using the chi-squared test and Fisher's Exact test) were used to determine associations between the accuracy groups and the mentioned variables. Food choice data were also analysed separately for each accuracy group by income category to control for the effect of income on food choice. Statistical significance was taken at the 5\% level.

\section{Results}

\section{Antbropometry and accuracy of self-reported weight} The mean ( \pm SD) age, weight (self-reported and actual), height and BMI of the total group as well as the three accuracy groups are presented in Table 1. There was a statistically significant difference between self-reported and actual weight of the total group and on average the study group underestimated their weight by -0.8 ( \pm 3.6$) \mathrm{kg}$, which indicates a slight tendency towards under-reporting. However, because this difference was less than $\pm 2 \mathrm{~kg}$ for the total group, it can be concluded that the weight estimation of the total group can be seen as accurate, as the latter was defined to be actual weight $\pm 2 \mathrm{~kg}$. However, categorisation of the individuals according to the accuracy groups indicated that only half of the study group estimated their weight accurately, while the rest either under- or overestimated their weight (Table 1). The analysis of variance (ANOVA) showed a statistically significant difference between the age, weights (self-reported and actual), heights and the BMI of the accuracy groups. The correct reporters had the lowest weight and BMI and were the oldest, whereas under-reporters were the heaviest, the tallest and had the highest BMI, while over-reporters were the youngest (Table 1).

\section{Demographic and general bealth variables}

Although no significant association between accuracy of self-reported weight and education was evident, it was found that under-reporters tended to be more likely to have grade 12 or tertiary education (Table 2). The underreporters were significantly more likely to have a higher income, while over-reporters were significantly more likely 
Table 2 Column percentages for demographic and health variables by accuracy group $(n=130)$

\begin{tabular}{|c|c|c|c|c|}
\hline & $>2 \mathrm{~kg}$ under-reported & $\pm 2 \mathrm{~kg}$ correct reported & $>2$ kg over-reported & $P$-value \\
\hline $\begin{array}{l}\text { Education } \\
\text { School up to grade } 10 \\
\text { Grade } 12 \\
\text { Tertiary education } \\
n^{*}\end{array}$ & $\begin{array}{l}2.7 \\
46.0 \\
51.4 \\
37\end{array}$ & $\begin{array}{l}23.2 \\
37.7 \\
39.1 \\
69\end{array}$ & $\begin{array}{l}20.8 \\
41.7 \\
37.5 \\
24\end{array}$ & $\begin{array}{l}0.1 \\
\text { chi-square }\end{array}$ \\
\hline $\begin{array}{l}\text { Income } \\
\text { R0-2999 } \\
\text { R3000-4999 } \\
\text { R5000+ } \\
n^{\star}\end{array}$ & $\begin{array}{l}27.0 \\
21.6 \\
51.4 \\
37\end{array}$ & $\begin{array}{l}44.9 \\
33.3 \\
21.7 \\
69\end{array}$ & $\begin{array}{l}45.8 \\
20.8 \\
33.3 \\
24\end{array}$ & $\begin{array}{l}0.03 \\
\text { chi-square }\end{array}$ \\
\hline $\begin{array}{l}\text { Use of contraceptive pill } \\
\text { Yes } \\
\text { No } \\
n^{\star}\end{array}$ & $\begin{array}{l}5.4 \\
94.6 \\
37\end{array}$ & $\begin{array}{l}10.1 \\
89.9 \\
69\end{array}$ & $\begin{array}{l}29.2 \\
70.8 \\
24\end{array}$ & $\begin{array}{l}0.02 \\
\text { Fisher's Exact test }\end{array}$ \\
\hline $\begin{array}{l}\text { Currently smoking } \\
\text { Yes } \\
\text { No } \\
n^{*}\end{array}$ & $\begin{array}{l}25.0 \\
75.0 \\
12\end{array}$ & $\begin{array}{l}54.2 \\
45.8 \\
24\end{array}$ & $\begin{array}{l}33.3 \\
66.7 \\
12\end{array}$ & $\begin{array}{l}0.2 \\
\text { chi-square }\end{array}$ \\
\hline
\end{tabular}

${ }^{*} n$ varies owing to unanswered questions.

to use the contraceptive pill (Table 2). No significant differences were found between the three accuracy groups regarding maximum and minimum weight in the past, smoking in the past and current smoking, although the correct reporters were more likely to be smoking currently (Table 2). If the actual number of cigarettes smoked in the past is considered, a significant difference is evident between the three groups, with the under-reporters having smoked the most cigarettes per day in the past (Table 1).

\section{Nutrition variables}

The average score of the total group for the nutrition knowledge questionnaire was $73 \%$ (Table 1). There was no significant difference in nutrition knowledge between the three accuracy groups (Table 1). Regarding food choices, it was found that over- and under-reporters were significantly more likely to eat hard, full-fat cheese with those in the lowest income group among the under-reporters being the most likely to eat full-fat cheese (Table 3). Although not significant, under-reporters tended to be more likely to eat chocolates and to drink spirits, with those in the middle income group of the over-reporters being the most likely to drink spirits (Table 3). Over-reporters tended to be more likely to eat fried potatoes (French fries, 'slap' chips, roast potatoes) and potato crisps, to drink six or more glasses of water per day, and to drink dry wine (Table 3). Those in the lower income group of the over-reporters were the most likely to eat potato crisps. Both the under- and overreporters were significantly more likely to drink diet soft drinks than were correct reporters. No significant differences or tendencies towards differences between the three accuracy groups were evident for the intake of fried fish, fried chicken, processed meat products, fatty meats, full cream milk, deep-fried bakery items, pies, tarts and pizzas, rich sauces, salad dressings and mayonnaise, cream, sour cream and cream cheese, eating fat on meat, adding fat in preparation of food, spreading butter/margarine on bread, nuts, non-diet soft drinks, sherry, liqueur, ice-cream, desserts, puddings, biscuits, jam and honey, adding sugar to vegetables, using sugar in tea/coffee, a creamer in tea/ coffee and condensed milk in coffee, total vegetables, $\mathrm{salad} / \mathrm{raw}$ vegetables and fresh fruit. Eating habits, depicted by the eating of breakfast, snacks and the number of meals consumed per day, did not differ significantly between the three accuracy groups.

\section{Psychological variables}

No significant differences were found between the three accuracy groups concerning the Eating Inventory, Beck Inventory, stress vulnerability questionnaire, self-esteem questionnaire and family functioning questionnaire. Results for the total group indicate that the subjects were inclined to have a score below the cut-off point for cognitive restraint and perceived hunger and a clinically significant score (above the cut-off point) for disinhibition (Eating Inventory). Further, the depression score (Beck Inventory) for the total group was indicative of mild depression. The respondents also seemed to have been stress-vulnerable (stress vulnerability questionnaire) and to have had a low self-esteem (self-esteem questionnaire).

\section{Pbysical activity}

No significant differences between the three accuracy groups were found regarding the amount and type of exercise and activity level at employment, although underreporters tended to be more likely to describe their employment as very active.

The variables that demonstrated a significant difference or a trend towards a difference between the underreporters, correct reporters and over-reporters in this study, are summarised in Table 4. 
Table 3 Column percentages for food choices and drinks by accuracy group $(n=31)$

\begin{tabular}{|c|c|c|c|c|}
\hline & $>2 \mathrm{~kg}$ under-reported & $\pm 2 \mathrm{~kg}$ correct reported & $>2$ kg over-reported & $P$-value \\
\hline $\begin{array}{l}\text { Hard full-fat } \\
\text { cheese }\end{array}$ & $\star *$ & & & \multirow[t]{4}{*}{$\begin{array}{l}0.04 \\
\text { chi-square test }\end{array}$} \\
\hline Sometimes & 8.1 & 29.4 & 20.8 & \\
\hline Daily & 27.0 & 11.8 & 29.2 & \\
\hline$n^{*}$ & 37 & 68 & 24 & \\
\hline Fried potato & & & & \multirow{3}{*}{$\begin{array}{l}0.06 \\
\text { Fisher's Exact tes }\end{array}$} \\
\hline Daily & 0 & 0 & 8.3 & \\
\hline$n^{\star}$ & 37 & 68 & 24 & \\
\hline Potato crisps & & & $* \star *$ & \multirow{4}{*}{$\begin{array}{l}0.2 \\
\text { Fisher's Exact test }\end{array}$} \\
\hline Sometimes & 59.5 & 63.8 & 41.7 & \\
\hline Regularly & 37.8 & 27.5 & 41.7 & \\
\hline Daily & 2.7 & 8.7 & 16.7 & \\
\hline Daily & 21.6 & 13.0 & 8.3 & \multirow{2}{*}{$\begin{array}{l}0.06 \\
\text { chi-square test }\end{array}$} \\
\hline$n^{*}$ & 37 & 69 & 24 & \\
\hline Water intake & & & & \multirow[t]{6}{*}{0.07} \\
\hline 0 glasses/day & 13.2 & 7.3 & 8.3 & \\
\hline 1-2 glasses/day & 47.4 & 36.2 & 29.2 & \\
\hline 3-4 glasses/day & 34.2 & 37.7 & 25.0 & \\
\hline$>6$ glasses/day & 5.3 & 18.8 & 37.5 & \\
\hline$n^{*}$ & 38 & 69 & 24 & \\
\hline Diet soft & & & & \multirow{5}{*}{$\begin{array}{l}0.02 \\
\text { Fisher's Exact test }\end{array}$} \\
\hline drink intake & & & & \\
\hline 0 cans & 31.6 & 58.8 & 37.5 & \\
\hline $1-2$ cans/week & 26.3 & 20.6 & 29.2 & \\
\hline 3-4 cans/week & 21.1 & 13.2 & 4.2 & \\
\hline No & 58.3 & 66.7 & 86.7 & \multirow{3}{*}{$\begin{array}{l}0.2 \\
\text { chi-square test }\end{array}$} \\
\hline Yes & 41.7 & 33.3 & 13.3 & \\
\hline$n^{*}$ & 24 & 48 & 15 & \\
\hline
\end{tabular}

* Varies owing to unanswered questions.

** Lower income group significantly more likely to eat hard full-fat cheese (Fisher's Exact $P=0.049$ ).

$\star \star \star$ Lower income group significantly more likely to eat potato crisps (Fisher's Exact $P=0.017$ )

${ }^{\star \star \star \star *}$ Middle income group significantly more likely to drink spirits (Fisher's Exact $P=0.029$ ).

\section{Discussion}

\section{Accuracy of self-reported weight}

The results indicate that, when evaluated as a group, overweight/obese women attending the CWMP reported their weight accurately. Stunkard and Albaum ${ }^{18}$, in a study of American women, reported similar results. The fact that subjects in this study endeavoured to be selected for admission to the weight loss programme, could have served as motivation to report their weight correctly. The slight tendency to under-report weight by the group as a whole is in concurrence with trends found in the literature ${ }^{3,4,6,7}$. Factors such as the time lapse between the completion of the application forms and actual weighing (1-2 months), and differences in accuracy between home scales and the scales used for this research, could explain some of the variance that was observed. However, these results are not representative of the individual reporter, as under-, correct- and over-reporting became evident when individuals were classified according to accuracy of selfreported weight. It is therefore suggested that self-reported weight can be used for the interpretation of data concerning overweight/obese groups, but not for the interpretation of individual data. 
Table 4 Summary of the characterisation of the three accuracy groups

\begin{tabular}{|c|c|c|}
\hline Under-reporters & Correct reporters & Over-reporters \\
\hline $\begin{array}{l}\text { Highest measured weight* } \\
\text { Highest BMI* }^{\star} \text { Tallest }^{\star} \\
\text { Highest education }^{\star \star} \\
\text { Highest income } \\
\text { Smoked most cigarettes/day in the past* } \\
\text { Highest intake of hard, full fat cheeses } \\
\text { (especially low income group*) } \\
\text { Higher intake of chocolate } \\
\text { Higher intake of spirits } \\
\text { High intake of diet soft-drinks } \\
\text { Described work as very active }\end{array}$ & $\begin{array}{l}\text { Lowest measured weight* } \\
\text { Lowest BMI* }^{\star} \\
\text { Highest age* } \\
\text { Smoke currently }{ }^{\star \star}\end{array}$ & 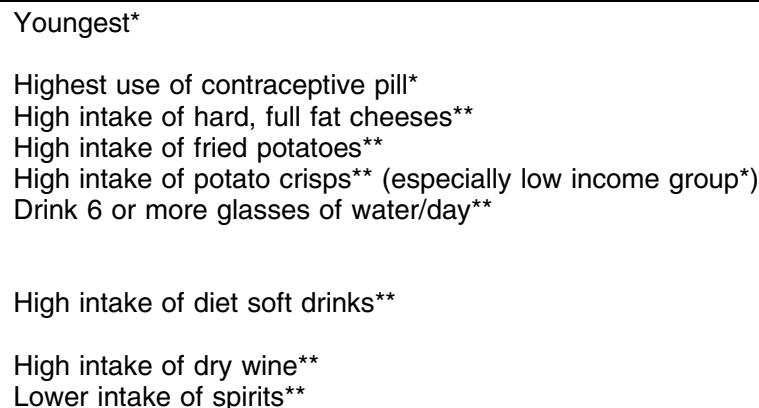 \\
\hline
\end{tabular}

* Significant differences.

** Tendency towards a difference.

\section{Characterisation of accuracy groups}

Heavier, taller subjects tended to under-report their weight, which is in concurrence with the results reported by Schlichting et al. ${ }^{9}$ and Palta et $a l^{7}$ Older women in this study reported their weight more accurately, as was reported by Palta et $a l^{7}{ }^{7}$, although the general trend found in the literature is for older females to under-report their weight ${ }^{6,18,19}$. The reasons for older women underreporting could be two-fold. First, it is common for people to try to keep things as they were when they were young and second, weight gain is usually associated with ageing. By diminishing awareness of their actual weight, women might be clinging to youthfulness by imagining themselves to have a lower weight, and therefore under-reporting ${ }^{6}$. The accurate self-reporting by older women in this study could possibly be ascribed to the fact that they wanted to be selected for the weight loss programme. Over-reporters were significantly more inclined to use the contraceptive pill, which can possibly be explained by the finding that they were the youngest and most probably still in their reproductive years.

As was found by Pirie et $a l^{4}{ }^{4}$, women in this study with higher education levels and income, thus those with a higher socio-economic status, were more likely to underreport their weight. However, Palta et $a l^{7}$ found that women who did not have a college education were more likely to under-report their weight. Boström and Diderichsen $^{19}$ also found that women in lower socio-economic groups underestimated their BMI. Jalkanen et al. ${ }^{6}$ concluded that females who had a higher family income were more aware of their weight and thus estimated their weight more correctly. Correct weight estimation by women in higher income groups could be because they are more actively involved in weight management, especially as they have more access to resources that aid in weight loss, such as weight loss programmes and diet foods ${ }^{20}$. However, in current Western society obesity is stigmatised and strong societal pressures for thinness exist ${ }^{21-23}$. These influences increase with rising socio-economic status and exert their influence on women more than on $\operatorname{men}^{21,22}$. As weight reporting can be seen as a form of social self-presentation ${ }^{3}$, overweight and obese people in the higher socio-economic group will be pressurised to under-report their weight ${ }^{24}$ (as was found in this study) in order to fit in with a socially desirable image.

The relatively high average score obtained for nutrition knowledge in all three accuracy groups demonstrates that all of the female overweight or obese outpatients have a reasonably good nutrition knowledge. It can be speculated that this knowledge is partly obtained through continuous exposure to different diets, as was also concluded by Burns et al. $^{25}$

The data obtained in this study concerning characterisation of accuracy groups according to food choices seem to be unique, since no similar data could be found. These data indicate that under-reporters were more likely to consume hard, full-fat cheese, chocolates, diet soft drinks and spirits. Under-reporters in the lower income group were the most likely to eat hard, full-fat cheese. Over-reporters were also more likely to consume hard, full-fat cheeses and diet soft drinks, as well as fried potatoes, potato crisps, dry wine and six or more glasses of water per day. Over-reporters in the middle income group were the most likely to consume spirits, while those in the lower income group were most likely to consume potato crisps. The under- and overreporters had the highest BMI of the three groups, which could be a reflection of their higher preference for foods high in fat, alcohol and simple carbohydrates ${ }^{26}$.

No difference between the three accuracy groups was evident regarding the psychological variables, with results for the total group following expected trends. The clinically significant average score obtained for the disinhibition factor on the Eating Inventory questionnaire seems to be a characteristic of obese individuals, as Bjorvell et al. ${ }^{27}$ also reported that obese subjects score higher on disinhibition than non-obese subjects. The mildly depressed state and low self-esteem found in this group also seem to be characteristic of obese women $^{28,29}$. In westernised societies obese people are exposed to discrimination and prejudice $^{30,31}$. This could lead to a lowering of self-esteem and 
subsequently depression. Further, overweight and obese individuals are more likely to follow a restricted diet and are also more likely to experience physical health problems, both of which are associated with depression ${ }^{32}$. Worries about weight and shape $\mathrm{e}^{33,34}$, a negative body image $^{31,35}$ and feelings of guilt and shame about their inability to control their weight ${ }^{36}$ could also induce negative self-esteem in obese women.

When considering these results and those of other researchers concerning the characteristics of weight estimation accuracy groups, it becomes evident that no clear pattern emerges and that the results are contradictory, which makes it difficult to formulate definite conclusions regarding the characteristics of under-reporters, correct reporters and over-reporters. It is recommended that further research should be conducted on similar and other South African groups, and subsequently be integrated with the results of this and international research to ensure reliable characterisation of weight estimation accuracy groups. Such data could make an important contribution towards interpreting data obtained by researchers who are forced to make use of self-reporting methods.

\section{Conclusion}

In conclusion, the results of this study indicated that, as a total group, female overweight or obese subjects attending a comprehensive weight management programme reported their weight with reasonable accuracy, with a slight tendency towards under-reporting. However, categorisation of the respondents according to accuracy of selfreported weight indicated that individual reporting was less accurate. Therefore, self-reported weight of groups of overweight or obese women could be a valid and reliable indicator of actual weight, but self-reported weight of such individuals cannot be interpreted similarly. Furthermore, certain characteristics could be attributed to under-reporters, correct reporters and over-reporters, but more research in this regard seems prudent before final conclusions can be drawn.

\section{References}

1 Stewart AW, Jackson RT, Ford MA, Beaglehole R. Underestimation of relative weight by use of self-reported height and weight. Am. J. Epidemiol. 1987; 25(1): 122-6.

2 Tell GS, Jeffery RW, Kramer FM, Snell MK. Can self-reported body weight be used to evaluate long-term follow-up of a weight-loss program? J. Am. Diet. Assoc. 1987; 87(9): 1198201.

3 Cash TF, Counts B, Hangen J, Huffine CE. How much do you weigh? Determinants of validity of self-reported body weight. Percept. Mot. Skills 1989; 69: 248-50.

4 Pirie P, Jacobs D, Jeffery R, Hannan P. Distortion in selfreported height and weight data. J. Am. Diet. Assoc. 1981; 78 601-6.

5 Stewart AL. The reliability and validity of self-reported weight and height. J. Chronic Dis. 1982; 35: 295-309.
6 Jalkanen L, Tuomiletho J, Tanskanen A, Puska P. Accuracy of self-reported body weight compared to measured body weight. Scand. J. Soc. Med. 1987; 15: 191-8.

7 Palta M, Prineas RJ, Berman R, Hannan P. Comparison of selfreported and measured height and weight. Am. J. Epidemiol. 1982; 115(2): 223-30.

8 Wing RR, Epstein LH, Ossip DJ, LaPorte RE. Reliability and validity of self-report and observers' estimates of relative weight. Addict Behav. 1979; 4: 133-40.

9 Schlichting P, Høilund PF, Quaade F. Comparison of selfreported height and weight in women and men. Int. J. Obes. 1981; 5: 67-76.

10 Bray GA. Definition, measurement and classification of the syndromes of obesity. Int. J. Obes. 1978; 2: 99-112.

11 Beck AT. Depression Inventory (Manual). Philadelphia: Centre for Cognitive Therapy, 1978.

12 Stunkard AJ, Messick F. Eating Inventory (Manual). Philadelphia, New York: Psychological Corporation, 1988.

13 Robson P. The development of a new self-report questionnaire to measure self-esteem. Psychol. Med. 1989; 19: 513.

14 Miller LA, Smith A. Stress: can we cope? Time 1983; 6: 66.

15 Olson D, Partner J, Levee Y. Faces III (Manual). Family Social Science. University of Minnesota, 1985.

16 Tibbs J. Evaluation of a Comprehensive Weight Control Program for Obesity Management: The Considerations of Psychological Factors in Treatment Outcome. M.A. thesis, University of Cape Town, 1996.

17 SAS Institute Inc. SAS/STAT ${ }^{\mathrm{TM}}$ User's Guide: Version 6, 4th edition. Cary, NC: SAS Institute Inc., 1989.

18 Stunkard AJ, Albaum JM. The accuracy of self-reported weights. Am. J. Clin. Nutr. 1981; 34: 1593-9.

19 Boström G, Diderichsen F. Socioeconomic differentials in misclassification of height, weight and body mass index based on questionnaire data. Int. J. Epidemiol. 1997; 26: 860-6.

20 Sobal J, Cassidy CM. Dieting foods: Conceptualizations and explanations. Ecol. Food Nutr. 1987; 20: 89-96.

21 Sobal J, Stunkard AJ. Socioeconomic status and obesity: A review of the literature. Psychol. Bull. 1989; 105(2): 260-75.

22 Stunkard AJ, Sobal J. Psychosocial consequences of obesity. In: Brownell KD, Fairburn CG, eds. Eating Disorders and Obesity: A Comprehensive Handbook. New York: Guilford Press, 1995: 417-21.

23 WHO Consultation on Obesity. Obesity: Preventing and managing the global epidemic. Report of a WHO Consultation on Obesity. Geneva: World Health Organisation, 1997: 125-38.

24 Ross CE, Mirowski J. Social epidemiology of overweight: A substantive and methodological investigation. J. Health Soc. Behav. 1983; 24: 288-98.

25 Burns CM, Richman R, Caterson ID. Nutrition knowledge in the obese and overweight. Int. J. Obes. 1987; 11(5): 485-92.

26 Swinburn B, Ravussin E. Energy balance or fat balance? Am. J. Clin. Nutr. 1993; 57(Suppl.): 766-71.

27 Bjorvell H, Rossner S, Stunkard A. Obesity, weight loss and dietary restraint. Int. J. Eating Disorders 1986; 5: 727-34.

28 Wadden TA, Stunkard AJ. Psychosocial consequences of obesity and dieting. In: Stunkard AJ, Wadden TA, eds. Obesity: Theory and Therapy. New York: Raven Press, 1993: 166.

29 Berman WH, Berman ER, Heymsfield S, Fauci M. The incidence and comorbidity of psychiatric disorders in obesity. J. Pers. Disord. 1992; 6(2): 168-75.

30 Wadden TA, Stunkard AJ. The psychological and social complications of obesity. Ann. Intern. Med. 1985; 103: $1062-7$.

31 Stunkard AJ, Wadden TA. Psychological aspects of severe obesity. Am. J. Clin. Nutr. 1992; 55: S524-32.

32 Ross CE. Overweight and depression. J. Health Soc. Behav. 1994; 35: 63-79.

33 Wadden TA, Brown G, Foster GD, Linowitz JR. Salience of weight related worries in adolescent males and females. Int. J. Eating Disorders 1991; 10: 407-14. 
34 Wadden TA, Foster GD, Stunkard AJ, Linowitz JR. Dissatisfaction with weight and figure in obese girls: discontent but not depression. Int. J. Obes. 1989; 13: 89-97.

35 Cash TF. Body-image attitudes among obese enrollees in a commercial weight-loss program. Percept. Mot. Skills 1993; 77 : $1099-103$.
36 Wadden TA, Foster GD. Behavioral assessment and treatment of markedly obese patients. In: Wadden TA, Van Itallie TB, eds. Treatment of the Seriously Obese Patient. New York: Guilford Press, 1992: 290-330. 